\title{
Increasing the biorelevance of simulated intestinal fluids for better predictions of drug equilibrium solubility in the fasted upper small intestine
}

\author{
Nikolaos Koumandrakis, Maria Vertzoni, Christos Reppas* \\ Department of Pharmaceutical Technology, Faculty of Pharmacy, National and Kapodistrian University of Athens, \\ Panepistimiopolis, 15771 Zografou, Greece
}

*Corresponding Author: E-mail: reppas@pharm.uoa.gr; Tel.: +30 210727 4678; Fax: +30 2107274027

Received: May 25, 2014; Published: July 18, 2014

\begin{abstract}
To date the importance of luminal species other than bile salts and phosphatidylcholine on drug equilibrium solubility in the fasted upper small intestine has been evaluated to a very limited extent. In this communication the importance of fatty acids, cholesterol, and proteins on solubility of four model lipophilic compounds was evaluated by including these components into previously proposed simulated intestinal fluids. Data were compared with ex vivo solubility data in aspirates reflecting the mean and the median luminal composition in the upper small intestine. It is concluded that estimation of solubility in aspirates reflecting the median luminal composition is better estimated when the presence of cholesterol and fatty acids is also simulated. In contrast, estimation of solubility in aspirates reflecting the mean luminal composition requires consideration of additional factors (e.g. buffer species identity, non-micellar colloidal structures, and lyso-phosphatidylcholine content).
\end{abstract}

Keywords: human intestinal fluids; biorelevant media; danazol; indomethacin; cinnarizine; ketoconazole

\section{Introduction}

Drug equilibrium solubility in the contents of upper intestinal lumen is an important factor for the oral absorption process as it determines the maximum dose which can be absorbed and it affects luminal drug dissolution rates. In case the active pharmaceutical ingredient (API) is lipophilic, luminal colloidal species (e.g. mixed bile salt micelles) greatly enhance luminal solubility and relevant information is crucial for predictions of drug plasma levels after oral administration of conventional dosage forms, e.g. when physiologically based pharmacokinetic modelling approaches are applied [1].

Luminal equilibrium solubility can be estimated by data in simulated intestinal fluids [e.g. 2,3]. Composition of relevant fluids is a balance between the actual luminal environment, the importance of specific luminal components, and, sometimes, the costs associated with their reproducible preparation methods and storage conditions. To date, the importance of certain luminal components which may have an impact on luminal solubility of lipophilic APIs in the fasted state, such as fatty acids, cholesterol and 
proteins, has not been considered. Such components have been recently shown to have a role in luminal precipitation of lipophilic weak bases [4].

The objective of this communication was to evaluate the usefulness of various fasted state simulating intestinal fluids in predicting solubility in the upper small intestine of four model lipophilic compounds (Table 1) with emphasis to components which are present in the upper small intestine but their importance has not been evaluated to date. Simulated intestinal fluids were prepared by using crude bile salt material which had been previously analyzed in our laboratory for its exact bile salt content. Data in simulated intestinal fluids were compared with data in human aspirates. Since it is not clear whether the average luminal composition should be considered on the basis of mean or of median luminal composition [5], in the present study two pooled aspirates samples that reflected the mean and the median luminal composition were used.

Table 1. Physicochemical characteristics of the model compounds used in this study

\begin{tabular}{ccccc}
\hline \hline & $\begin{array}{c}\text { Cinnarizine } \\
{[6-8]}\end{array}$ & $\begin{array}{c}\text { Ketoconazole } \\
{[9,10]}\end{array}$ & $\begin{array}{c}\text { Indomethacin } \\
{[9]}\end{array}$ & $\begin{array}{c}\text { Danazol } \\
{[11]}\end{array}$ \\
\hline Molecular Weight & 368.5 & 531.4 & 357.8 & 337.5 \\
clogP & 5.19 & 3.65 & 3.66 & 4.5 \\
pKa & 7.78 & 2.94 and 6.51 (both alkaline) & 4.5 & - \\
$\begin{array}{c}\text { Aqueous Solubility } \\
(\mu \mathrm{g} / \mathrm{mL})\end{array}$ & 0.29 & 0.0866 & 0.937 & 1.1 \\
\hline \hline
\end{tabular}

\section{Experimental}

Cinnarizine was from Janssen Cilag AEBE (lot \# 1001105726, Athens, Greece), ketoconazole was from Recordati Espana S.L. (lot \# 03000051, Beniel, Spain), indomethacin was from F.I.S. Fabrica Italiana Sintetici S.p.A. (lot \# 0907105123, Vicenza, Italy) and danazol was from Sanofi-Aventis (batch \# F510357, Fawdon, France). Egg lecithin (Lipoid E PC, > 98 \% phosphatidylcholine) was from Lipoid GmbH (Ludwigshafen, Germany). Ox bile salt extract was from Fluka Chemie GmbH, Germany (product No 86340, lot \# 386645/1 12601). According to our HPLC-CAD analysis [12] the total bile salts content of the crude material used in the presenet study is $71.5 \% \mathrm{w} / \mathrm{w}$, and the following bile acids are present: taurocholic $22.2 \% \mathrm{w} / \mathrm{w}$, glycocholic $24.7 \% \mathrm{w} / \mathrm{w}$, taurochenodeoxycholic $1.7 \% \mathrm{w} / \mathrm{w}$, ursodeoxycholic $7.1 \% \mathrm{w} / \mathrm{w}$, glycochenodeoxycholic $1.3 \% \mathrm{w} / \mathrm{w}$, cholic $7.5 \% \mathrm{w} / \mathrm{w}$, glycodeoxycholic $7.1 \% \mathrm{w} / \mathrm{w}$. [3]. Albumin from bovine serum, BioChemika Fraction V was from Fluka (cat \# 05488, lot \# S31293-466). Methanol and acetonitrile of HPLC grade were from E. Merck (Darmstadt, Germany). Water purified with Labconco water pro ps system (Kansas City, Missouri, USA) was used in all procedures. All other chemicals were of analytical grade.

Individual human aspirates were collected from the ligament of Treitz after receiving approval by the Ethical Committee of the Red Cross Hospital of Athens (A.P. 497 / 06.12.2011). Samples were selected and pooled so that the pooled sample had composition similar to the mean composition of intraluminal contents [5], HIFmean. In addition, samples were selected and pooled so that the pooled sample had composition similar to the median composition of intraluminal contents [5], HIFmedian (Table 2). Due to multiple freeze - thawing processes, $\mathrm{pH}$ of both HIFmean and HIFmedian used in the solubility measurements was increased from 6.5 (aspiration time) to 7.5.

FaSSIF [13] and FaSSIF-V2 [2] reflect the mean environment in the fasted upper small intestine. Recently, FaSSIF-V2Plus was proposed for predicting the precipitation of weak bases in the upper small 
intestine [4]. In the present investigation, all these media were prepared by using crude bile material (ox bile salt extract) and used for measuring the solubility of the four model APIs (Table 1). The importance of phosphatidylocholine concentration $(0.75,1,1.5 \mathrm{mM})$ and of bovine serum albumin concentration (BSA $0.5-4 \mathrm{mg} / \mathrm{ml}$ ) on the predictability of luminal solubility of ketoconazole, indomethacin and danazol were also evaluated. Compositions of simulated intestinal fluids used in the presented study is shown in Table 2. Finally, solubilities of ketoconazole, indomethacin and danazol were also measured in buffer solutions of phosphates and maleates having $\mathrm{pH}$ values of 6.5.

Solubilities were measured in triplicate using the shake-flask method. For solubility measurements in human intestinal fluids, $1 \mathrm{ml}$ of HIF and pure drug powder in excess $(1 \mathrm{mg}$ for cinnarizine, $15 \mathrm{mg}$ for ketoconazole, $5 \mathrm{mg}$ for indomethacin and $1 \mathrm{mg}$ for danazol) were transferred into 2 -ml polypropylene vials. Vials were then sealed with polypropylene caps, and put in an oscillating water bath $\left(37^{\circ} \mathrm{C}\right)$. Equilibration times were experimentally determined or had already been determined previously using similar media volumes (1-5 $\mathrm{ml})$ and the same in vitro setup [3,10,14,15]. Equilibration times were $2 \mathrm{~h}$ (cinnarizine), $8 \mathrm{~h}$ (ketoconazole), $2 \mathrm{~h}$ (indomethacin) and $4 \mathrm{~h}$ (danazol). After reaching equilibrium, and since HIFs could not be filtered through $0.45 \mu \mathrm{m}$ filters, samples were centrifuged for $10 \mathrm{~min}$ at $11500 \mathrm{~g}$ at $37{ }^{\circ} \mathrm{C}$. After measuring the $\mathrm{pH}$, the supernatant was appropriately diluted with acetonitrile, centrifuged again (10 min, $11500 \mathrm{~g}, 10^{\circ} \mathrm{C}$ ) and assayed for drug concentration using validated HPLC-UV methods. For solubility measurements in simulated intestinal fluids, $5 \mathrm{ml}$ of the medium and pure drug powder in excess $(5 \mathrm{mg}$ for cinnarizine, $175 \mathrm{mg}$ for ketoconazole, $25 \mathrm{mg}$ for indomethacin and $5 \mathrm{mg}$ for danazol) were transferred into $10-\mathrm{ml}$ polypropylene vials. Vials were then sealed with high density polypropylene caps and put in an oscillating water bath $\left(37^{\circ} \mathrm{C}\right)$ for periods identical to those used in the experiments in human intestinal fluids (please see above). After reaching equilibrium, samples were filtered through $0.45 \mu \mathrm{m}$ regenerated cellulose filters (adsorption to filters was measured to be negligible), the filtrates were diluted appropriately diluted with acetonitrile and assayed for their drug content using validated HPLC-UV methods.

APIs were evaluated for their stability in solubility media prior to solubility measurements. Ketoconazole, indomethacin and danazol were found to be stable in all media tested in this study. For cinnarizine, a portion of the pooled sample reflecting HIFmean was transferred in a test tube, cinnarizine in excess was added, the tube was sealed and it was incubated at $37{ }^{\circ} \mathrm{C}$ in a shaking water bath. Four hours after the initiation of shaking the contents of the tube were centrifuged $\left(11500 \mathrm{~g}, 37^{\circ} \mathrm{C}, 10 \mathrm{~min}\right) . \mathrm{pH}$ of the supernatant was measured to be 7.8. A sample from the supernatant was analyzed immediately for its cinnarizine content (content at time $\mathrm{t}=0$ ) and the remaining was transferred in another tube, sealed and incubated for 20 hours at $37{ }^{\circ} \mathrm{C}$ in the same shaking water bath. Samples were obtained $0.5,1,1.5,2,3.2$ and 20 hours after the initiation of the incubation of the filtrate.

All model compounds were assayed with HPLC-UV methods (Table 3). For each drug/medium combination, quantification was based on linear standard curves constructed using the same medium and identical sample handling procedure. 


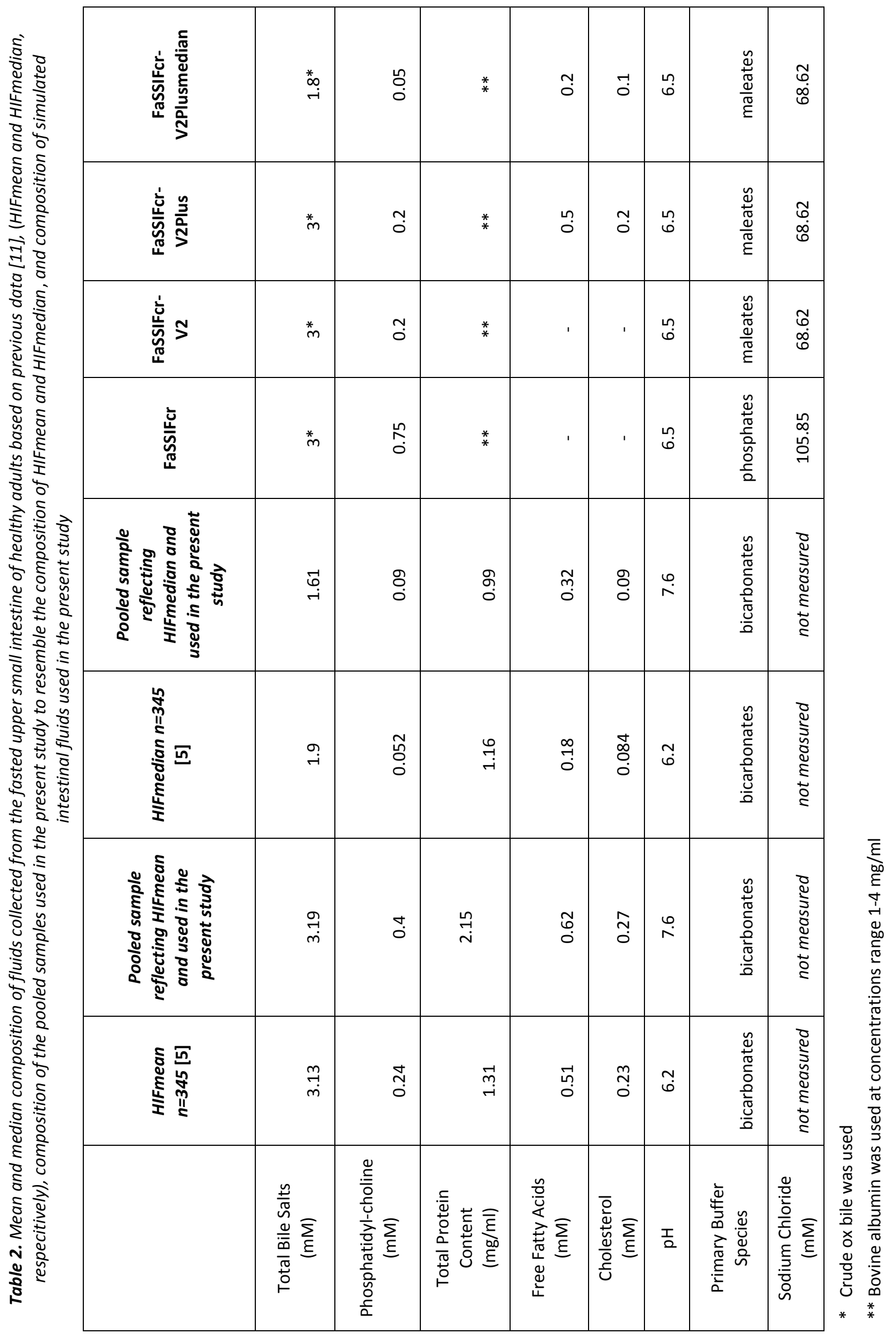


Table 3. The chromatographic conditions used for the analysis of drugs in the present study

\begin{tabular}{|c|c|c|c|c|}
\hline $\begin{array}{l}\text { Chromatographic } \\
\text { Conditions }\end{array}$ & Cinnarizine & Ketoconazole & Indomethacin & Danazol \\
\hline Column & $\begin{array}{c}\text { Fortis } C_{18} \\
(150 \times 4.6 \mathrm{~mm}, 5 \mu \mathrm{m})\end{array}$ & $\begin{array}{c}\text { BDS C }_{18} \\
(250 \times 4.6 \mathrm{~mm}, 5 \mu \mathrm{m})\end{array}$ & $\begin{array}{c}\text { BDS C }_{18} \\
(250 \times 4.6 \mathrm{~mm}, 5 \mu \mathrm{m})\end{array}$ & $\begin{array}{c}\text { BDS C }_{18} \\
(250 \times 4.6 \mathrm{~mm} \\
5 \mu \mathrm{m})\end{array}$ \\
\hline Mobile Phase & $\begin{array}{c}\text { Methanol-water- } \\
\text { triethylamine-acetic acid } \\
\text { 75:25:0.4:0.6 v/v/v/v }\end{array}$ & $\begin{array}{c}\text { methanol-water- } \\
\text { diethylamine } \\
74: 26: 0.1\end{array}$ & $\begin{array}{c}\text { Acetonitrile-water- } \\
\text { acetic acid 70:30:05 } \\
\text { v/v/v }\end{array}$ & $\begin{array}{c}\text { acetonitrile-water } \\
55: 45 \mathrm{v} / \mathrm{v}\end{array}$ \\
\hline Flow Rate (ml/min) & 1 & 1 & 1 & 1.3 \\
\hline $\begin{array}{l}\text { Detection wavelength } \\
\text { (nm) }\end{array}$ & 254 & 240 & 266 & 286 \\
\hline Injection volume $(\mu \mathrm{l})$ & 20 & 20 & 20 & 20 \\
\hline
\end{tabular}

\section{Results and Discussion}

Cinnarizine was unstable in the pooled HIF sample reflecting HIFmean. Figure 1 shows the cinnarizine degradation profile in the pooled HIF sample at $37{ }^{\circ} \mathrm{C}$ together with the characteristics of the best fitted line drawn by using the data up to $3.20 \mathrm{~h}$. Estimated degradation half-life is $1.44 \mathrm{~h}$. Interestingly, solubility of cinnarizine has been previously reported to be $32.0 \pm 11.8 \mu \mathrm{g} / \mathrm{ml}$ and $47.3 \pm 17.4 \mu \mathrm{g} / \mathrm{ml}$ in HIFs and FaSSIF, respectively [16]. After reaching equilibrium in plain phosphate and plain maleate buffers filtrates were incubated at $37{ }^{\circ} \mathrm{C}$ for $48 \mathrm{~h}$ at which time their cinnarizine content was measured to be zero. Therefore, stability of cinnarizine in simulated intestinal media is also an issue. During the equilibration period, concentration peaked at $4 \mathrm{~h}$ after initiation of oscillation, and this was considered as "apparent cinnarizine solubility". Apparent solubility in FaSSIFcr-V2Plus was significantly higher than in FaSSIFcr-V2 (Figure 2), i.e. inclusion of sodium oleate and cholesterol in increased the solubility of cinnarizine. This is in line with the high lipophilicity of the compound (Table 1 ) and previously collected data on the effects of lipids on the solubilization capacity of mixed bile salt micelles for highly lipophilic compounds [17].

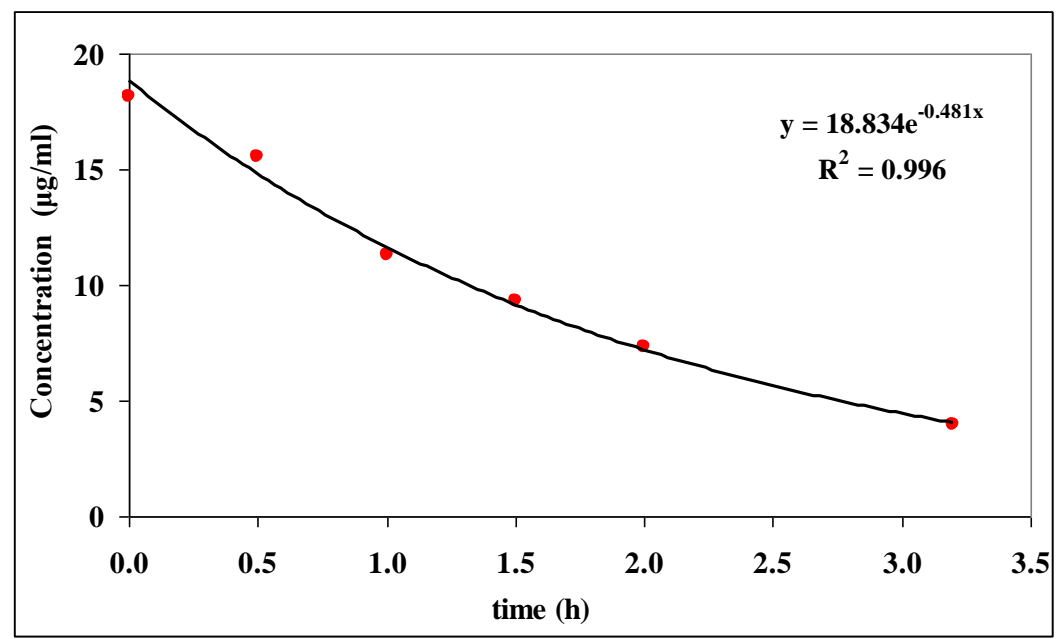

Figure 1. Cinnarizine concentration in the pooled HIF sample reflecting HIFmean as a function of time after initiation of incubation $\left(37^{\circ} \mathrm{C}\right)$. 


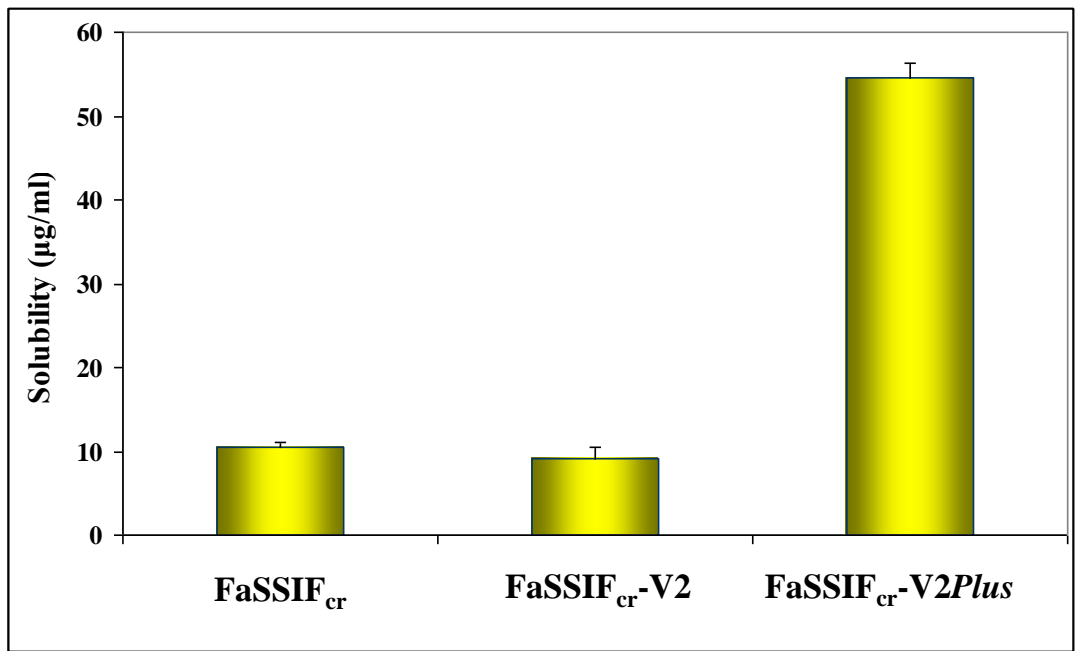

Figure 2. Mean+SD ( $n=3)$ apparent cinnarizine solubility in simulated intestinal fluids $\left(37^{\circ} \mathrm{C}\right)$. Please see in Table 2 and in the text for compositions of simulated intestinal fluids.

FaSSIFcr-V2 was less useful than FaSSIFcr in the prediction of ketoconazole, indomethacin, and danazol solubility in the pooled sample reflecting HIFmean (Figure 3). Unlike with cinnarizine, inclusion of biorelevant concentrations of cholesterol and sodium oleate in FaSSIFcr-V2 (i.e. FaSSIFcr-V2Plus) did not have significant impact on solubility of ketoconazole and danazol. Also, the impact of BSA on ketoconazole, indomethacin, and danazol solubility in FaSSIFcr and FaSSIFcr-V2 was minimal (data not shown). This is in line with previous data indicating that luminal proteins may not be important to luminal drug solubility or their global simulation should be done cautiously [3]. In contrast, by increasing phosphatidylocholine concentration in FaSSIF-V2 to $1 \mathrm{mM}$, ketoconazole and danazol solubility in the pooled sample reflecting HIFmean were successfully estimated (FaSSIFcr-V21,PC, Figure 3).

FaSSIFcr-V2plusmedian led to successful estimation of luminal solubility of ketoconazole and danazol in the pooled sample reflecting HIFmedian (Figure 4).

For indomethacin, solubility was underestimated in all cases, due to the higher than average $\mathrm{pH}$ of the pooled samples reflecting HIFmean and HIFmedian; $\mathrm{pH}$ has much greater impact on indomethacin solubility than the rest of APIs tested in the present study, due to its specific ionization properties (Table 1, Figures 3 and 4). 

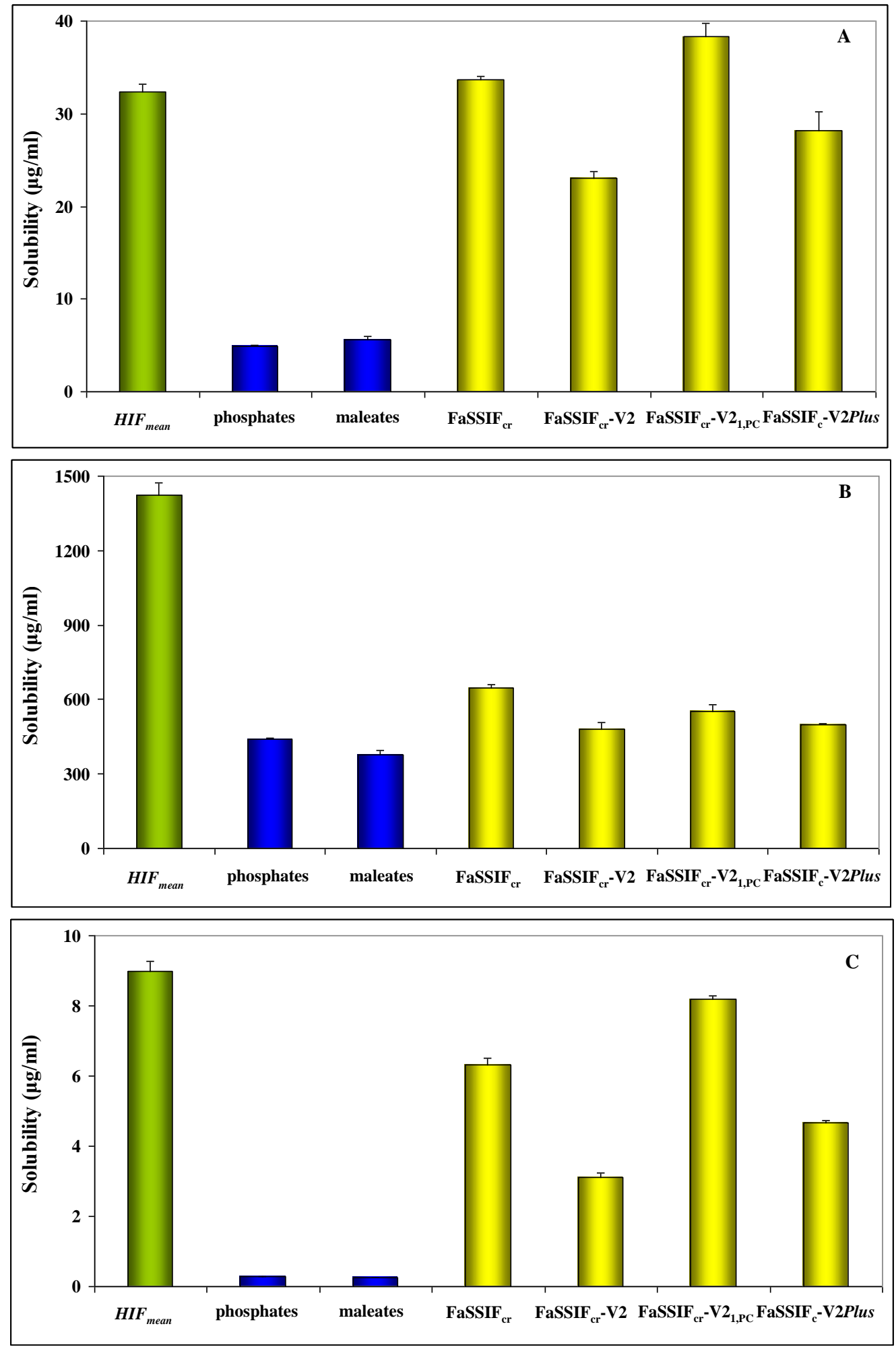

Figure 3. Mean+SD ( $n=3)$ values for solubility of ketoconazole $(A)$, indomethacin $(B)$, and danazol $(C)$ in the pooled HIF sample reflecting HIFmean, and in various simulated intestinal fluids $\left(37^{\circ} \mathrm{C}\right)$. Please see Table 2 and text for composition of simulated intestinal fluids. 

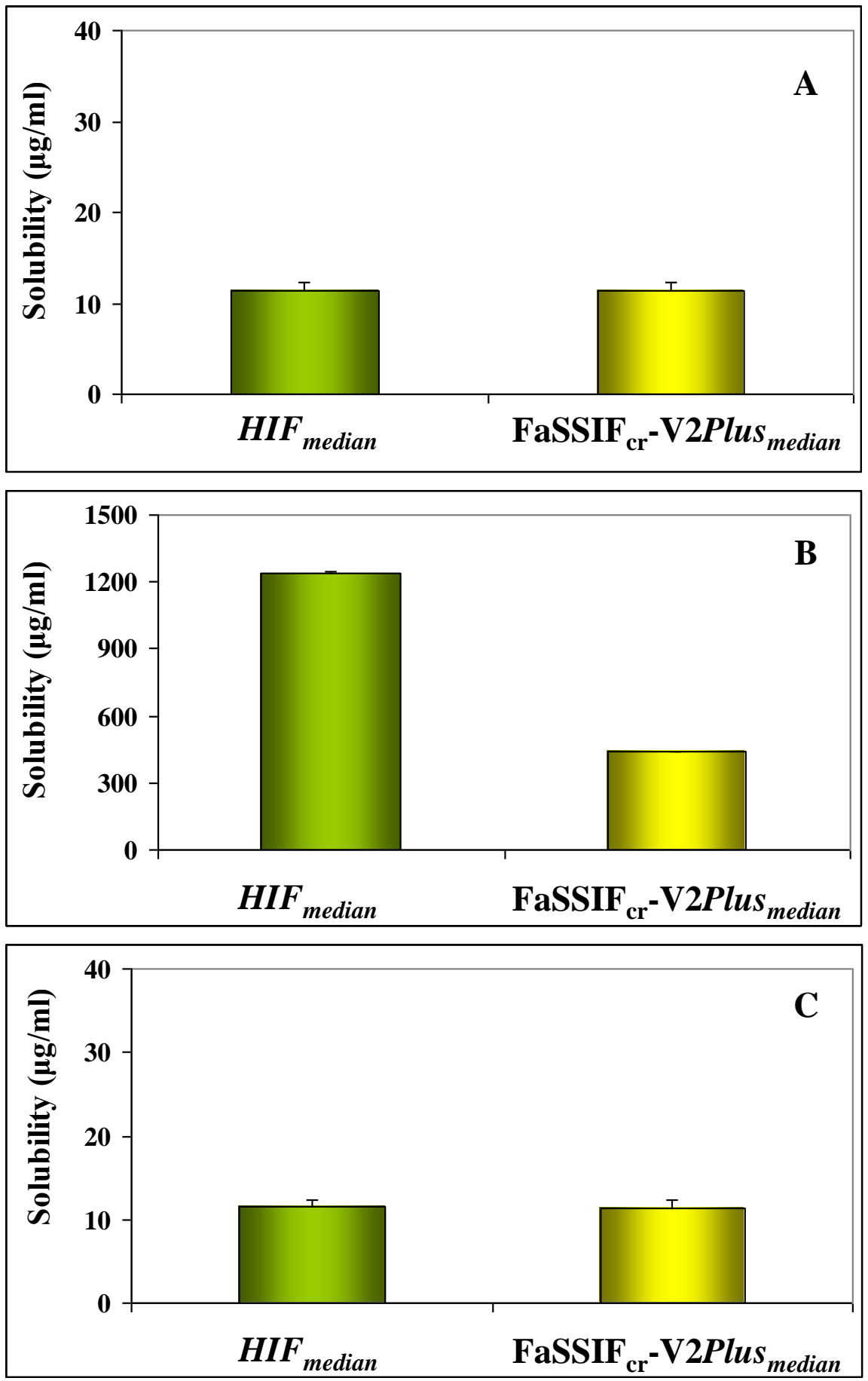

Figure 4. Mean+SD ( $n=3)$ values for solubility of ketoconazole $(A)$, indomethacin $(B)$ and danazol $(C)$ in the pooled HIF sample reflecting HIFmedian and in FaSSIFcr-V2Plus median.

\section{Concluding remarks}

Estimation of solubility in median environment of upper small intestine in the fasted state seems adequate by data collected in FaSSIF-V2plusmedian. In contrast, if solubility in the mean environment of upper small intestine is to be estimated, consideration of additional luminal characteristics is required, e.g. buffering species identity [18], non-micellar colloidal lipid structures [19], and lyso-phosphatidylcholine content [20]. Perhaps a practical methodology to balance the lack of simulation of certain luminal components in FaSSIF-V2 might be the use of FaSSIF-V2 with high phosphatidylcholine concentration, e.g. $1 \mathrm{mM}$. 


\section{Acknowledgement}

Part of this work was presented as a poster at the $9^{\text {th }}$ World Meeting on Pharmaceutics, Biopharmaceutics and Pharmaceutical Technology, 31 March to 3 April 2014, Lisbon, Portugal.

\section{References}

[1] E.S. Kostewicz, L. Aarons, M. Bergstrand, M.B. Bolger, A. Galetin, O. Hatley, M. Jamei, R. Lloyd, X. Pepin, A. Rostami-Hodjegan, E. Sjögren, C. Tannergren, D.B. Turner, C. Wagner, W. Weitschies, J. Dressman. Eur. J. Pharm. Sci. 57 (2014) 300-321.

[2] E. Jantratid, N. Janssen, C. Reppas, J.B. Dressman. Pharm. Res. 25 (2008) 1663-76.

[3] M. Vertzoni, A. Diakidou, M. Chatzilias, E. Söderlind, B. Abrahamsson, J.B. Dressman, C. Reppas. Pharm. Res. 27 (2010) 2187-2196.

[4] D. Psachoulias, M. Vertzoni, J. Butler, D. Busby, M. Symillides, J. Dressman, C. Reppas. Pharm. Res. 29 (2012) 3486-3498.

[5] D. Psachoulias, M. Vertzoni, K. Goumas, V. Kalioras, S. Beato, J. Butler, C. Reppas. Pharm. Res. 28 (2011) 3145-3158.

[6] http://www.vcclab.org/lab/alogps/ (accessed 21 May 2014)

[7] S. Clarysse, J. Brouwers, J. Tack, P. Annaert, P. Augustijns Eur. J. Pharm. Sci. 43 (2011) 260-269.

[8] C.H. Gu, D. Rao, R.B. Gandhi, J. Hilden, K. Raghavan. J. Pharm. Sci. 94 (2005) 199-208.

[9] http://redpoll.pharmacy.ualberta.ca/drugbank/index.html (accessed 21 May 2014)

[10] M. Vertzoni, E. Pastelli, D. Psachoulias, L. Kalantzi, C. Reppas. Pharm. Res. 24 (2007) 909-917.

[11] E.M. Persson, A.S. Gustafsson, A.S. Carlsson, R.G. Nilsson, L. Knutson, P. Forsell, G. Hanisch, H. Lennernäs, B. Abrahamsson. Pharm. Res. 22 (2005):2141-2151.

[12] M.Vertzoni, H. Archontaki, C. Reppas. J. Lipid Res. 49 (2008) 2690-2695.

[13] E. Galia, E. Nicolaides, D. Hoerter, R. Loebenberg, C. Reppas, J.B. Dressman Pharm. Res. 15 (1998) 698-705.

[14] M. Vertzoni, C. Markopoulos, M. Symillides, C. Goumas, G. Imanidis, C. Reppas. Mol. Pharm. 9 (2012) 1189-1198.

[15] L. Kalantzi, E. Persson, B. Polentarutti, B. Abrahamsson, K. Goumas, J.B. Dressman, C. Reppas. Pharm. Res. 23 (2006) 1373-1381.

[16] P. Augustijns, B. Wuyts, B. Hens, P. Annaert, J. Butler, J. Brouwers. Eur J Pharm Sci. 57 (2014) 322332.

[17] G.A. Kossena, W.N. Charman, B.J. Boyd, C.J. Porter. J. Pharm. Sci. 94 (2005) 481-492.

[18] G. Garbacz, B. Kołodziej, M. Koziolek, W. Weitschies, S. Klein. Eur. J. Pharm. Sci. 51 (2014) 224-231.

[19] A. Müllertz, D. Fatouros, J. Smith, M. Vertzoni, C. Reppas. Mol. Pharm. 9 (2012) 237-247.

[20] A. Fuchs, B. Kloefer, M. Leigh, J. Dressman. AAPS Annual Meeting, November 10-14, 2013, San Antonio, Texas, USA (poster). 